\title{
The output for the Master's degree in Science Communication at SISSA of Trieste
}

\author{
Donato Ramani, Nico Pitrelli
}

What professional future awaits those who have attended a school in science communication? This has become an ever more urgent question, when you consider the proliferation of Masters and post-graduate courses that provide on different levels a training for science communicators in Europe and all over the world. In Italy, the International School for Advanced Studies of Trieste has been for fourteen years now the seat for a Master's degree in Science Communication that has graduated over 170 students. This letter illustrates the results of a survey carried out in order to identify the job opportunities they have been offered and the role played in their career by their Master's degree. Over $70 \%$ of the interviewees are now working in the field of science communication and they told us that the Master has played an important role in finding a job, thus highlighting the importance of this school as a training, cultural and professional centre.

Established in 1993, the Master's degree in Science Communication of the International School for Advanced Studies (SISSA-ISAS) of Trieste is a part-time two-year course whose purpose is to train scientific communicators in different fields: press, radio, TV and on-line journalism, institutional and business communication, traditional and multi-media publishing, museology. It is addressed to graduates in any subjects who access the school after sitting an admission exam with an average number of applicants that in the past has ranged from 60 to 100 a year. Usually 15 to 20 people are admitted each year. The Master's degree envisages a final thesis on a subject in the science communication field.

Since 2002, and every two years, former students has had to fill in a questionnaire to gather information on their career after taking their Master's degree. This letter illustrates the results of the survey carried out in 2006 that has involved all of the students who attended the course from its first year (academic year 1993-1994) and its twelfth year (academic year 2004-2005). The survey involved only those students who obtained a Master's degree, whereas it excluded students who had retired from the course or those who, although they attended the full course, had not obtained the degree. The total number of students meeting this criterion who were subsequently contacted is 175 . The questionnaire has been filled in by 165 students, equalling $94,3 \%$ of the total sample.

The questionnaire was designed on the basis of the guidelines offered by a research on the Italian Master's degrees carried out by the Italian Ministry for University and Scientific Research in $2004 .{ }^{1}$ Thanks to it, it has been possible to analyse the role played by this Master's degree in the subsequent career of its students, the professional fields the interviewees are working in and their opinion regarding the training the degree provided to them.

\section{Tasks in the field of science communication by students and former students}

The questionnaire has analysed the activity in the field of science communication the students or former students have performed and the working areas they have been employed in. On this subject, the question asked was:

«Have you carried out any science communication task in the past 12 months?»

The possible answers were the following:

As a job (full time, part-time, occasional ones) 
$\square$ As an extra-job activity, hobby, etc.

No tasks

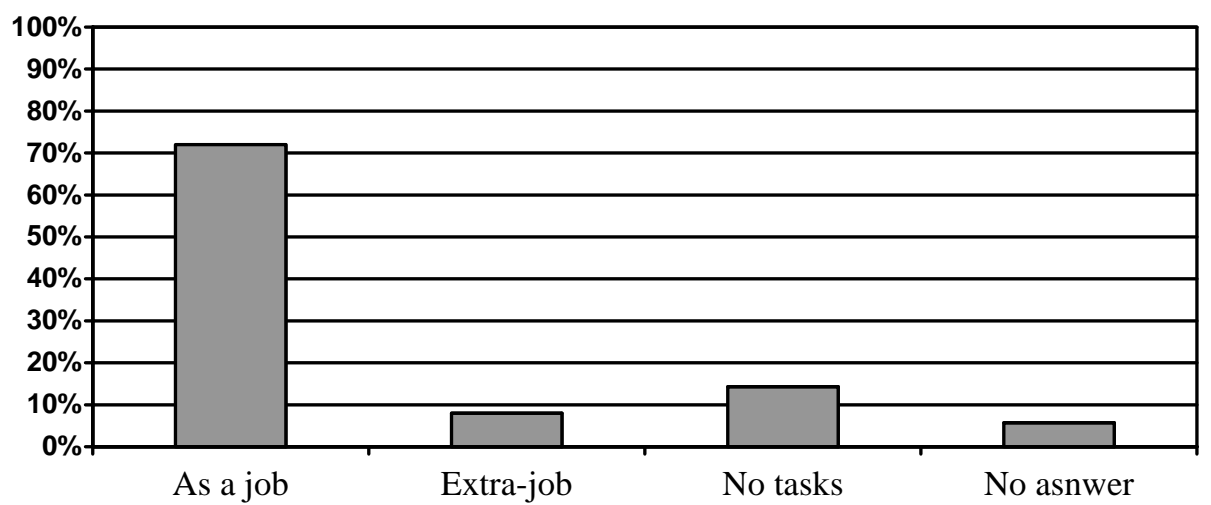

Graph 1. The interviewees' working activity in the field of science communication. 126 people out of 175 , equalling $72 \%$, said that they perform science communication tasks "as a job".

Those who answered "as a job" (126 out of 175) were also asked how often they have performed science communication tasks in the past twelve months.

The possible answers were the following:
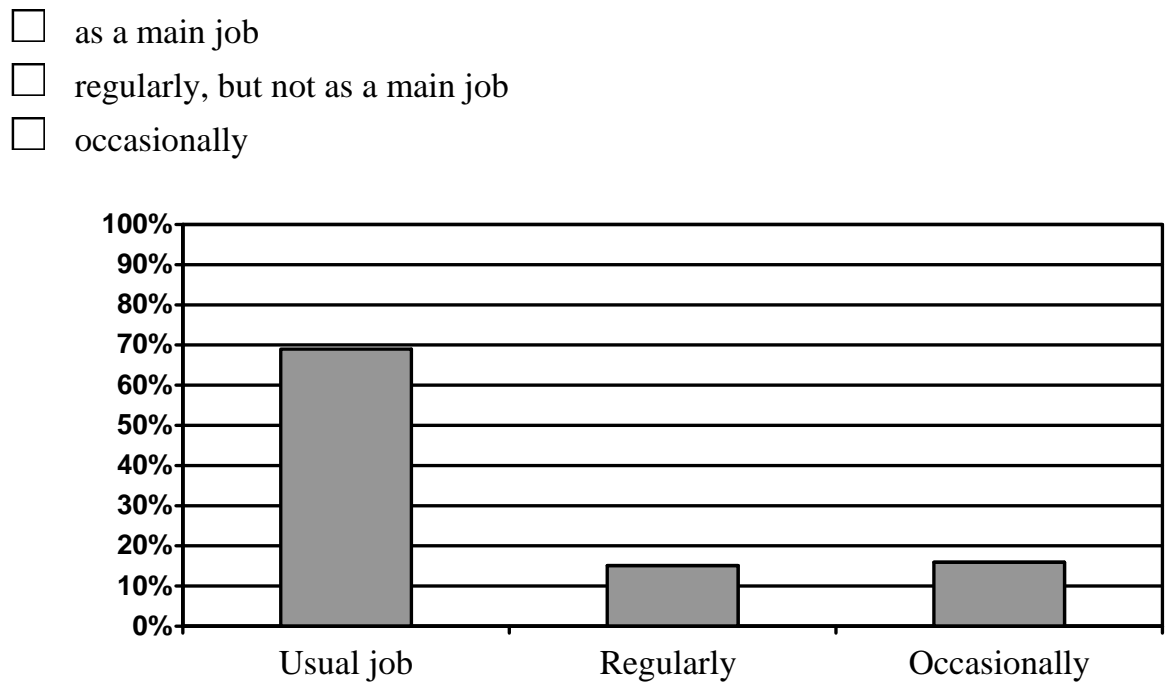

Graph 2. Frequency of the working activity in science communication performed by students or former students of the Master's degree (percentages out of 126 students).

\section{Working areas}

To identify the range of the activities in the field of science communication performed by the interviewees, the following question was asked:

«What science communication areas does your job involve?»

The possible answers were the following:

Journals 


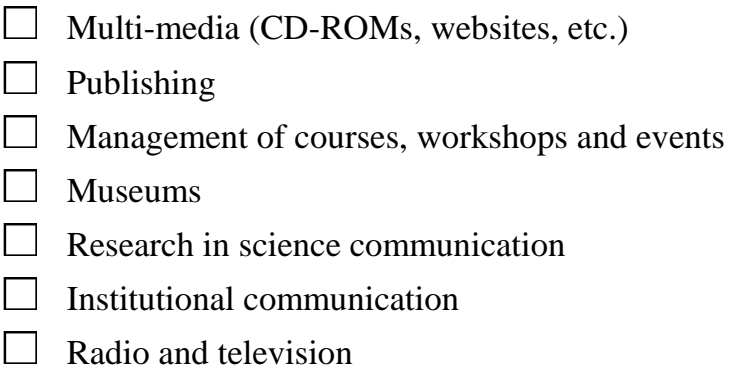

Interviewees could select more than one field. Graph 3 shows the percentages for the answers given by the interviewees who said they perform science communication tasks as their main job.

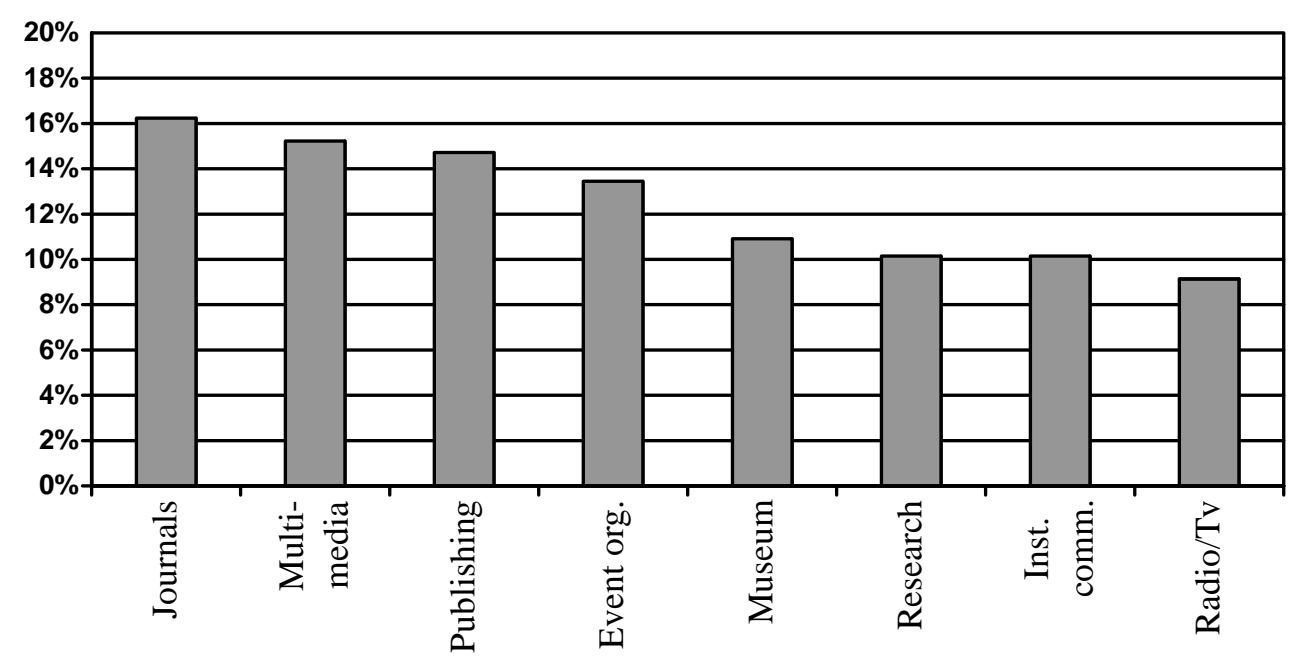

Graph 3. Employment percentage in the various sectors for those performing science communication tasks as a main job.

\section{Has the Master's degree been helpful?}

Furthermore, the questionnaire asked for an assessment of the Master's degree and its usefulness, also as regards the chance to find a job. The questions were the following:

«To what extent has the Master helped you in finding your present job? (the reference is to the job you carry out as your main activity)»

The possible answers were the following:
$\square$ It was crucial
$\square$ It contributed to a great extent
$\square$ It contributed to a some extent only
$\square$ It did not have any relevance
$\square$ No answer 


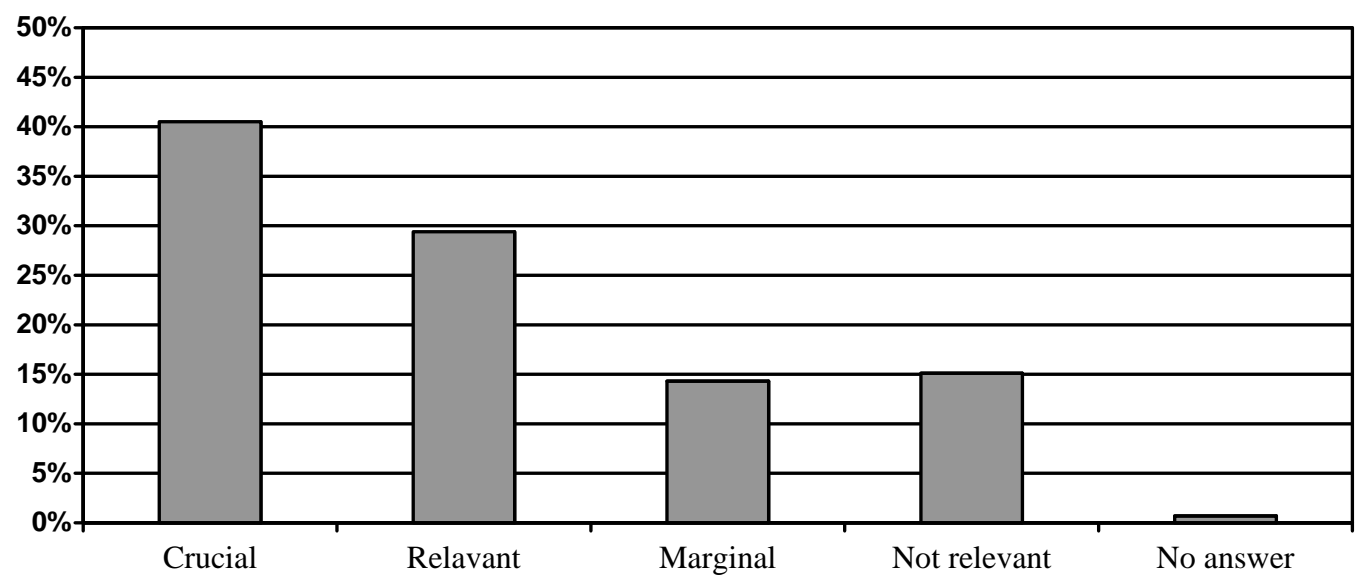

Graph 4. Role played by the Master's degree in finding a job. This question only regards the interviewees who said they carry out science communication tasks "as their job".

«Do you think that taking or having taken the Master has turned out to be useful...»

The students could select one or more answers to this question.

\begin{tabular}{|l|l|}
\hline & selection \# \\
\hline As a cultural enrichment & 147 \\
\hline For the contacts it provides & 129 \\
\hline For one's professional training & 114 \\
\hline For the job opportunities it offers & 54 \\
\hline As an academic qualification & 36 \\
\hline To progress in your career & 5 \\
\hline In economic terms, for your earnings & 3 \\
\hline As a human experience & 2 \\
\hline It is not useful & 0 \\
\hline
\end{tabular}

Table 1. Usefulness of the Master according to the interviewees.

\section{Translated by Massimo Caregnato}

\section{Notes}

\footnotetext{
${ }^{1}$ Ministero dell'Istruzione, dell'Università e della Ricerca - Comitato nazionale per la valutazione del sistema universitario,

Indagine nazionale sui Master universitari.Il ruolo delle università nella formazione professionale post-lauream, ottobre 2004.
} 